Journal of

Women's Health and Gynecology

\title{
Diagnostic Accuracy of Saline-Contrast Sonohysterography Guided Biopsy versus Office Biopsy in Endometrial Pathology: an Interventional Study
}

Faryal Khan ${ }^{1}$, Dania Al Jaroudi ${ }^{1}$, Aisha Mansoor Ali ${ }^{1}$, Abdulaziz Al-Obaid ${ }^{1}$, Mohamad Al-Tannir ${ }^{2 *}$

${ }^{1}$ Women's Specialized Hospital, King Fahad Medical City, Riyadh, Saudi Arabia

${ }^{2}$ Research Center, King Fahad Medical City, Riyadh, Saudi Arabia

${ }^{*}$ Corresponding author: Mohamad Al-Tannir, Research Center, King Fahad Medical City, King Fahad Medical City, Riyadh 11525, Saudi Arabia, Tel: +966-1-288-9999 Ext. 10850, Fax: +966 112889000 Ext.11299, E-mail: maltannir@kfmc.med.sa

Received Date: June 12, 2016; Accepted Date: August 31, 2016; Published Date: September 02, 2016

Citation: Faryal Khan, et al. (2016) Diagnostic Accuracy of Saline-Contrast Sonohysterography Guided Biopsy versus Office Biopsy in Endometrial Pathology: an Interventional Study. J Womens Health Gyn 1: 1-9.

\footnotetext{
Abstract

Purpose : The primary objective of this study is to evaluate the effectiveness of Saline Contrast Sonohysterography guided biopsy (SCSH GB) as compared with Endometrial Office Biopsy (EOB) in diagnosing endometrial pathologies by the adequacy of the sample and comparison of the pathologic diagnosis confirmed by hysteroscopy or hysterectomy (histological and anatomical).

Methods: Unselected consecutive 250 patients aged 40 years and above with AUB and abnormal endometrium on transvaginal ultrasound presenting to ultrasound unit and outpatient department at Women Specialized Hospital, King Fahad Medical City, Riyadh, KSA were screened for eligibility in this interventional study. Fifty percent of enrolled patients were initially booked for SCSH GB then scheduled for EOB. Whereas, the remaining $50 \%$ underwent EOB first and then had SCSH GB. This method was used to control the issue of insufficient biopsy. The diagnosis was categorized as 1) physiological 2) benign polyp or sub-mucous fibroid and 3) hyperplasia/cancer.

Results: Out of 113 patients 93 underwent both SCSH GB and EOB procedures and were entered into final data analysis. SCSH GB (94.6\%) achieved significantly higher sample adequacy compared to $86 \%$ of EOB (p<0.001). SCSHGB significantly diagnosed all $29(100 \%)$ polyps and sub-mucous fibroids confirmed by hysteroscopy/hysterectomy versus only 8 (27.5\%) cases by $\mathrm{EOB}(\mathrm{p}<0.001)$.

Conclusions: The SCSH GB technique can be a reasonable alternative to EOB in pre- and post-menopausal women aged 40 and older with AUB.

Keywords: Abnormal uterine bleeding, Endometrial Office Biopsy; Guided biopsy; Menopausal women; Saline Contrast Sonohysterography.

\section{Introduction}

Abnormal Uterine Bleeding (AUB) is the most common complaint of premenopausal and postmenopausal (PMB) women. Early and complete investigations are recommended to exclude endometrial pathology [1-4]. More than $40 \%$ of affected women with AUB have been reported to have intrauterine pathologies [5].

C 2016 The Authors. Published by the JScholar under the terms of the Creative Commons Attribution License http://creativecommons.org/licenses/

The most common causes of AUB in women are endometrial polyps, submucosal fibroids, and endometrial hyperplasia [6]. The reported incidence of endometrial carcinoma is 5\%$17 \%$; therefore, a thorough investigation of women with AUB is warranted $[2-4,7,8]$. Endometrial Office Biopsy (EOB) is one of the initial investigations for women with AUB who are over the age of 40 years $[1,3,4,9]$. However, most pathological lesions are found to be benign and are most often missed with blind sampling techniques [3,7,10-12].
} by $/ 3.0 /$, which permits unrestricted use, provided the original author and source are credited. 
The Saline Contrast Sonohysterography Guided Biopsy (SCSH GB) is another recommended and efficient method for diagnosing endometrial pathology $[4,10,13,14]$. Endometrial biopsy under diagnostic hysteroscopy is considered to be the 'gold standard' for the diagnosis of intrauterine abnormalities and is recommended for women with AUB [15]. However, it is expensive and invasive compared with SCSH GB and has proven to be unnecessary in $50 \%$ of all women who actually have normal uterine cavities $[4,7,16,17]$.

The primary objective of this study was to evaluate the effectiveness of SCSH GB compared with EOB in the diagnosis of endometrial pathologies among pre- and post-menopausal women with AUB. The efficacy of the two methods was determined by the adequacies of the samples obtained and by comparison of the pathological diagnosis (histological and sonographic) as confirmed by hysteroscopy or hysterectomy.

\section{Methods}

An interventional study was performed in the ultrasound department and outpatient department (OPD) between December 2012 and March 2014. Patients who were over the age of 40 years, had AUB and exhibited abnormal endometria on transvaginal ultrasound (TVS) fit the inclusion criteria. Whereas, those who were pregnant, had uterine carcinoma, refused to participate in the study or were planning to move away from our area were excluded from the study. The institutional review board granted approval to conduct this study. Unselected consecutive 250 patients were screened for enrolment in the study, of whom 137 (54.8\%) patients were either excluded from enrolment because they were not eligible according to the inclusion/exclusion criteria or they were not interesting to voluntary participate in the study. Thus, $113(45.2 \%)$ patients fulfilled the inclusion criteria and agreed to participate.

Patients were seen in the outpatient department at King Fahad Medical City by an obstetrics and gynecology (Ob/Gyn) physician and underwent a routine clinical assessment that included the basic demographic information, medical/family history, a routine physical examination, and initial laboratory investigations. These women were referred to the ultrasound department for two- and three-dimensional trans-vaginal ultrasound (2D and 3D TVS) as a routine initial investigation to determine the endometrial thickness. Qualified sonographers who were unaware of the purpose of the study performed the ultrasound. Patients who were found to have abnormal endometria (thickness $>4 \mathrm{~mm}$, inhomogeneous, indistinct margins or inconclusive) were asked to participate in the study.

The primary investigator obtained informed consent from those who agreed to participate in this study. Both procedures (SCSH GB and EOB) were performed by using a single lumen catheter (Uterine Explora, Model 1; 3 mm OD curette with a Vacu-Loc Syringe; Cooper Surgical, Berlin, Germany). An Ob/ Gyn physician, who was not aware of the study's objective, performed the EOBs as an outpatient procedure.
Fifty percent of enrolled patients were initially booked for SCSH GB then scheduled for EOB. Whereas, the remaining $50 \%$ underwent EOB first and then had SCSH GB. This method was used to control the issue of insufficient biopsy. The gap between the two interventions was at least 4 days.

The same patients were called between 5 to 10 day of last menstrual period (LMP) and pregnancy was excluded. A sterile bivalve vaginal speculum was used, and the cervix was visualised and cleaned with povidone iodine. The catheter was introduced through the cervix into the uterine cavity; the speculum was then removed, and a high-frequency (7 MHz) 3D trans-vaginal probe was introduced into the vagina. Following the visualisation of the endometrium, $10-20 \mathrm{ml}$ of saline was instilled into the uterine cavity, which distended the inner walls of the endometrium leading to easy detection of any endometrial lesion. The sampling procedure was then performed under direct vision of real-time $2 \mathrm{D}$ ultrasound guidance by delicate vacuum aspiration using the 5-ml syringe attached to the same catheter that was initially introduced. Gentle rotational and up-and-down movements were performed at the site of the lesion before the catheter was withdrawn. All cases were examined using the same machine (Philips iU22 3D ultrasound machine, Bothell, WA, USA) by a single operator to increase the reliability, precision, and accuracy. Both physicians were blinded to the histopathology results of the other biopsy while performing their respective intervention, which was released three weeks later.

The women were prospectively followed until the final diagnosis was achieved. The final diagnosis were categorised as follows: 1) physiological, i.e., one year of follow-up for the patients with physiological histopathology on the SCSH GB and EOB (physiological histopathology were defined as normal functional endometria in premenopausal women and atrophic endometria in PMB women) 2) benign polyps or submucosal fibroids and 3) hyperplasia/cancer. The second and third categories were confirmed by histological diagnosis obtained from hysteroscopy or hysterectomy, i.e., the gold standard.

\section{Result}

The mean age and parity of the 113 enrolled women were (48.9 $\pm 8.2)$ years and $(5.42 \pm 4.9)$, respectively Twenty-seven cases (29\%) were classified as PMB, and 86 (76.1\%) were classified as premenopausal bleeding. Among the latter group, 33 patients (38.3\%) had heavy menstrual bleeding, 35 (40.6\%) had irregular HMB and 18 (20.9\%) had inter-menstrual bleeding. One hundred nine patients underwent SCSH GB, and the procedure was well tolerated with no complications (4 patients were excluded due to cervical stenosis). EOB was performed in 97 women (11 women did not show up, and the catheter could not be introduced in 5 patients).

Out of the 113 enrolled patients ninety-three patients efficaciously underwent both SCSH GB and EOB procedures and were considered into final data analysis for sample adequacy and appropriate diagnosis. 
Sample adequacy: Among the 93 patients who had completed both procedures (SCSH GB and EOB), we found that $88(94.6 \%)$ patients out of the 93 had an adequate sample by SCSH GB procedure, and the remaining 5 (5.4\%) were inadequate. As well as, for $\mathrm{EOB}$ procedure, we found that $80(86 \%)$ patients out of the 93 had adequate sample, and 13 (14\%) were insufficient for histopathology. The sample adequacy of SCSH GB was significantly higher than that of EOB $(p=0.001)$.

Among the 5 inadequate samples obtained with SCSH GB, one was identified as a large polyp during the procedure and further confirmed by hysteroscopic polypectomy to be a benign endometrial polyp. It was further, observed that the four samples that were inadequate by SCSH GB were also inadequate by EOB, and normal endometria were detected on repeated 3DTVS after 1 month and physiological examination after 1-yearfollow-up. These four cases were false positive by 3DTVS.

Pathological diagnosis: Of the 93 women who underwent SCSH GB and EOB, 29 women required an intervention, and the diagnosis was confirmed by either hysteroscopy ( 25 cases) or hysterectomy (4 cases). The SCSH GB technique resulted in correct diagnosis in all 29 cases (100\%). In contrast, the EOB results agreed with the gold standard results in only 8 (27.5\%) cases and this difference was significant $(\mathrm{p}<0.001)$.

In this regard, SCSH GB results were obtained in 86 cases because 6 patients refused hysteroscopy, and one patient (age 54) died due to multiple medical conditions (Table 1). The sensitivity was $100 \%$ (95\% CI: $86.65 \%$ to $100 \%$ ), the specificity was $98.33 \%$ (95\% CI: $91.03 \%$ to $99.72 \%$ ), and the accuracy of the test was $98.33 \%$. The positive predictive value was $96.30 \%$ (95\% CI: $80.97 \%$ to $99.38 \%$ ), and the negative predictive value was $100 \%$ (95\% CI: $93.88 \%$ to $100 \%)$.

\begin{tabular}{|c|c|c|c|c|c|}
\hline & \multicolumn{4}{|c|}{ Final Outcome } & \\
\hline $\begin{array}{l}\text { SC- } \\
\text { SHGB } \\
\text { Diag- } \\
\text { nosis }\end{array}$ & $\begin{array}{l}\text { Physi- } \\
\text { ological }\end{array}$ & polyp & Fibroid & $\begin{array}{l}\text { Hyper- } \\
\text { plasia / } \\
\text { Malig- } \\
\text { nancy }\end{array}$ & Total \\
\hline $\begin{array}{l}\text { Physi- } \\
\text { ological }\end{array}$ & 59 & 0 & 0 & 0 & 59 \\
\hline Polyp & 0 & 17 & 0 & 1 & 18 \\
\hline Fibroid & 0 & 0 & 7 & 0 & 7 \\
\hline $\begin{array}{l}\text { Hyper- } \\
\text { plasia / } \\
\text { Malig- } \\
\text { nancy }\end{array}$ & 0 & 0 & 0 & 0 & 2 \\
\hline Total & 59 & 17 & 7 & 3 & 86 \\
\hline
\end{tabular}

Table 1: bSCSH combined GB diagnosis compared with Final Outcome $(\mathrm{N}=86)$

Kappa 0.975 (95\% confidence interval -0.926 to 0.998 )
Whereas in the 93 EOB cases, samples were insufficient for histopathology in $13(14 \%)$ cases and two $(2.2 \%)$ patients refused hysteroscopy, thus the final outcomes were obtained only in 78 (83.9\%) cases (Table 2). The sensitivity was $16 \%$ (95\% CI: $4.64 \%$ to $36.10 \%$ ), the specificity was $100 \%$ (95\% CI: $93.21 \%$ to $100 \%$ ), and the accuracy of this test was $73 \%$. The positive predictive value was $100 \%$ (95\% CI: $40.23 \%$ to $100 \%$ ), and the negative predictive value was $71.62 \%$ (95\% CI: $59.95 \%$ to $81.49 \%)$.

\begin{tabular}{|l|c|c|c|c|c|}
\hline \multirow{2}{*}{$\begin{array}{l}\text { EOB } \\
\text { Diag- } \\
\text { nosis }\end{array}$} & $\begin{array}{l}\text { Physi- } \\
\text { ological }\end{array}$ & polyp & Fibroid & $\begin{array}{c}\text { Hyper- } \\
\text { plasia / } \\
\text { Malig- } \\
\text { nancy }\end{array}$ & \\
\hline $\begin{array}{l}\text { Physi- } \\
\text { ological }\end{array}$ & 53 & 12 & 7 & 2 & 74 \\
\hline Polyp & 0 & 3 & 0 & 0 & 3 \\
\hline Fibroid & 0 & 0 & 0 & 0 & 0 \\
\hline $\begin{array}{l}\text { Hyper- } \\
\text { plasia / } \\
\text { Malig- } \\
\text { nancy }\end{array}$ & 0 & 0 & 0 & 1 & 1 \\
\hline Total & 53 & 15 & 7 & 3 & 78 \\
\hline
\end{tabular}

Table 2: 'Endometrial Biopsy diagnosis compared with Final Outcome $(\mathrm{n}=78)$

Kappa 0.1908 (95\% confidence interval -0.010 to 0.495$)$

\section{Discussion}

The SCHS GB has an added advantage of direct visualization (sonographic diagnosis) of the endometrial lesions and the 3 Dimensional study of the saved images, thus enhancing the diagnostic capability of SCSH $[18,19]$. Further, biopsies were obtained with $2 \mathrm{D}$ visual guidance. This explains the diagnosis of the seven cases of submucous fibroids which were missed by EOB because it is difficult to harvest myometrial tissue using an office sampling device. In contrast, EOB is a blind procedure and has the potential to miss many focal lesions $[10,11]$. Thus, it is evident from our study that EOB performed poorly in the diagnosis of endometrial pathology in pre and postmenopausal women with AUB, particularly those with focal lesions. EOB missed 19 of the 24 focal lesions (79.2\%), and this result is similar to that of a previous study [1].

Our study results are in agreement with the results of a prospective experimental study published in 2009 by Moschos et al in which SCSH endometrial sampling was found to provide a diagnosis in $89 \%$ of cases [1]. Similarly, another study conducted by Kraus and Boston on 54 patients with AUB who underwent SCSH GB endometrial sampling revealed the promising reliability and accuracy of this method as an initial investigation in addition to the good tolerance of this method in an outpatient setting [20]. 
Additionally, in 2007, Leone et al. concluded that SCSH-guided endometrial sampling is as good as hysteroscopic biopsy and should be considered a reliable outpatient procedure for women with AUB because it is very well tolerated and inexpensive [13].

The gold standard for the diagnosis of intrauterine abnormalities is diagnostic hysteroscopy combined with the histological examination of an endometrial aspiration or biopsy. However, hysteroscopy is invasive, reasonably expensive, time-consuming, and it is performed under general anaesthesia in some centres [8-10]. It is also associated with risks, such as uterine perforation and ascending genitourinary infection $[12,19]$. In contrast, SCSH GB has been proven to be a safe, cost-effective and comparative alternative diagnostic tool with a high level of accuracy and reliability in the initial diagnosis of women with AUB. Therefore, SCSH GB can reduce the number of patients undergoing hysteroscopy [21,22]. We recruited a larger sample size than those of previous studies and thus provided more reliable results $[1,20]$.

Our study corroborates the findings of previous studies, ensures the generalizability of these findings and has established that SCSH GB is an accurate and reliable tool for initial diagnostic investigations in pre- and post-menopausal women with AUB $[1,7,10]$. In addition to a previous study by Epstein et al. highlighted the limitations of blind procedures in postmenopausal women with abnormal uterine bleeding as 40 to $90 \%$ of polyps and $43-66 \%$ of hyperplasias respectively were missed by D\&C [23]. Furthermore, they indicated that both polyps and hyperplasia are risk factors for developing endometrial carcinoma [24]. Accordingly, D\&C is not the best technique of examining postmenopausal women bleeding. Thus, SCSH GB could be a better alternative than the blind procedures.

The limitation of our study in few cases was the inability to sustain uterine cavity distension due to the retrograde flow of the saline because the biopsy catheter did not have a balloon to occlude the internal OS. However, this difficulty was overcome by the rapidity of the automatic sweep of the 3D transducer. The uterine cavity distension can be effectively improved by substituting saline by gel instillation, but then compromising the image quality, until the air bubbles in the gel can be prevented [24]. Furthermore, all SCSH procedures were performed by the same sonologist; thus, inter-observer differences could not be monitored. However, it is now established that gynaecological ultrasound and SCSH GB can be performed by competent sonographers [11,14]. Additionally, in cases with heterogeneous uteruses and fibroids, shadowing partly obscured the cavity and caused difficulty in visualisation. Future developments in 3DTVS technology will overcome this concern.

SCSH GB was significantly superior to EOB in terms of sample adequacy and the diagnosis of endometrial pathologies. The SCSH GB technique can be a reasonable alternative to EOB in pre- and post-menopausal women aged 40 and older with AUB.

\section{Acknowledgments}

The authors acknowledge the efforts of Mr. Isamme AlFayyad for his assistance in preparing the manuscript.

\section{References}

1) Moschos E, Ashfaq R, McIntire DD, Liriano B, Twickler DM (2009) Saline-infusion sonography endometrial sampling compared with endometrial biopsy in diagnosing endometrial pathology. Obstet Gynecol 113: 881-887.

2) Dubinsky TJ, Reed S, Mao C, Waitches GM, Hoffer EK (2000) guided endometrial biopsy: technical feasibility. AJR Am J Roentgenol 174: 1589-1591.

3) O'Connell LP, Fries MH, Zeringue E, Brehm W (1998) Triage of abnormal postmenopausal bleeding: a comparison of endometrial biopsy and transvaginal sonohysterography versus fractional curettage with hysteroscopy. Am J Obstet Gynecol 178: 956-61.

4) Goldstein RB, Bree RL, Benson CB, Benacerraf BR, Bloss JD, et al. (2001) Evaluation of the woman with postmenopausal bleeding: Society of Radiologists in Ultrasound-Sponsored Consensus Conference statement. J Ultrasound Med 20: 1025-1036.

5) Farquhar C, Ekeroma A, Furness S, Arroll B (2003) A systematic review of transvaginal ultrasonography, sonohysterography and hysteroscopy for the investigation of abnormal uterine bleeding in premenopausal women. Acta Obstet Gynecol Scand 82: 493-504.

6) Ryu JA, Kim B, Lee J, Kim S, Lee SH (2004) Comparison of transvaginal ultrasonography with hysterosonography as a screening method in patients with abnormal uterine bleeding. Korean J Radiol 5: 39-46.

7) Epstein E, Ramirez A, Skoog L, Valentin L (2001) Transvaginal sonography, saline contrast sonohysterography and hysteroscopy for the investigation of women with postmenopausal bleeding and endometrium > 5 mm. Ultrasound Obstet Gynecol 18: 157-162.

8) Alfhaily F, Ewies AA (2009) The first-line investigation of postmenopausal bleeding: transvaginal ultrasound scanning and endometrial biopsy may be enough. Int J Gynecol Cancer 19: 892-895.

9) Dijkhuizen FP, Mol BW, Brölmann HA, Heintz AP (2000) The accuracy of endometrial sampling in the diagnosis of patients with endometrial carcinoma and hyperplasia: a meta-analysis. Cancer 89: 1765-1772.

10) Mihm LM, Quick VA, Brumfield JA, Connors AF Jr, Finnerty JJ (2002) The accuracy of endometrial biopsy and saline sonohysterography in the determination of the cause of abnormal uterine bleeding. Am J Obstet Gynecol 186: 858-860.

11) De Kroon CD, Jansen FW (2006) Saline infusion sonography in women with abnormal uterine bleeding: an update of recent findings. Curr Opin Obstet Gynecol 18: 653-657.

12) Kraus PA, Boston RJ (2001) Saline infusion sonohysterogram as initial investigation of the endometrium and uterine cavity. Aust N Z J. Obstet Gynaecol 41: 433-435.

13) Wei AY, Schink JC, Pritts EA, Olive DL, Lindheim SR (2006) Saline contrast sonohysterography and directed extraction, resection and biopsy of intrauterine pathology using a Uterine Explora Curette. Ultrasound Obstet Gynecol 27: 202-205.

14) Leone FP, Carsana L, Lanzani C, Vago G, Ferrazzi E (2007) Sonohysterographic endometrial sampling and hysteroscopic endometrial biopsy: a comparative study. Ultrasound Obstet Gynecol 29: 443-448. 
15) Erdem M, Bilgin U, Bozkurt N, Erdem A (2007) Comparison of transvaginal ultrasonography and saline infusion sonohysterography in evaluating the endometrial cavity in pre- and postmenopausal women with abnormal uterine bleeding. Menopause 14: 846-852.

16) Bernard JP, Metzger U, Camatte S, Robin F, Vildé F, Taurelle R et al. (2002) Comparison of three catheters for endometrial sampling during sonohysterography: results of a preliminary study. J Obstet Gynaecol 22: 84-85.

17) Salim R, Lee C, Davies A, Jolaoso B, Ofuasia E, Jurkovic D (2005) A comparative study of three-dimensional saline infusion sonohysterography and diagnostic hysteroscopy for the classification of submucous fibroids. Hum Reprod 20: 253-257.

18) Berridge DL, Winter TC (2004) Saline infusion sonohysterography: technique, indications, and imaging findings. J Ultrasound Med 23: 97-112.

19) Phillips V, McCluggage WG (2005) Results of a questionnaire regarding criteria for adequacy of endometrial biopsies. J Clin Pathol 58: 417-419.

20) Van den Bosch T, Vandendael A, Van Schoubroeck D, Wranz PA, Lombard CJ (1995) Combining vaginal ultrasonography and office endometrial sampling in the diagnosis of endometrial disease in postmenopausal women. Obstet Gynecol 85: 349-352.

21) Bingol B, Gunenc Z, Gedikbasi A, Guner H, Tasdemir S et al. (2011) Comparison of diagnostic accuracy of saline infusion sonohysterography, transvaginal sonography and hysteroscopy. J Obstet Gynaecol 31: 54-58.

22) de Kroon CD, de Bock GH, Dieben SW, Jansen FW (2003) Saline contrast hysterosonography in abnormal uterine bleeding: a systematic review and meta-analysis. BJOG 110: 938-947.

23) Epstein E, Ramirez A, Skoog L, Valentin L (2001) Dilatation and curettage fails to detect most focal lesions in the uterine cavity in women with postmenopausal bleeding. Acta obstetricia et gynecologica Scandinavica 80: 1131-1136.

24) Bij de Vaate AJ, Brölmann HA, van der Slikke JW, Emanuel MH, Huirne JA (2010) Gel instillation sonohysterography (GIS) and saline contrast sonohysterography (SCSH): comparison of two diagnostic techniques. Ultrasound Obstet Gyneco 35: 486-489.

Submit your manuscript to a JScholar journal and benefit from:

ब Convenient online submission

ฯ Rigorous peer review

I Immediate publication on acceptance

q Open access: articles freely available online

ब High visibility within the field

๑ Better discount for your subsequent articles

Submit your manuscript at

http://www.jscholaronline.org/submit-manuscript.php 